\title{
Properties of Lipoamide Dehydrogenase and Thioredoxin Reductase from Escherichia coli Altered by Site-Directed Mutagenesis $^{a}$
}

\author{
CHARLES H. WILLIAMS, JR,, ${ }^{b, c}$ NIGEL ALLISON, ${ }^{d, e}$ \\ GEORGE C. RUSSELL, ${ }^{d}$ ANDREW J. PRONGAY, \\ L. DAVID ARSCOTT, ${ }^{b}$ SHOMPA DATTA, ${ }^{b}$ \\ LENA SAHLMAN, ${ }^{b, f}$ AND JOHN R. GUEST ${ }^{d}$ \\ ${ }^{b}$ Veterans Administration Medical Center and \\ Department of Biological Chemistry \\ University of Michigan \\ Ann Arbor, Michigan 48105 \\ and \\ ${ }^{d}$ Department of Microbiology \\ Sheffield University \\ Sheffield SIO 2TN \\ United Kingdom
}

Lipoamide dehydrogenase and thioredoxin reductase are members of the pyridine nucleotide-disulfide oxidoreductase family of flavoenzymes, which is distinguished by an oxidation-reduction-active disulfide. ${ }^{1}$ Other members of the family, glutathione reductase and mercuric reductase, are homologous with lipoamide dehydrogenase in all domains. ${ }^{2-5}$ Thioredoxin reductase is homologous with the others only in its two adenosine binding regions; the remainder of the protein, including its active-site disulfide region, appears to have evolved convergently. ${ }^{6}$

Catalysis takes place in two half-reactions, as shown in FIGURE 1 for lipoamide dehydrogenase. ${ }^{7-9}$ In the first, dithiol-disulfide interchange effects reduction of the oxidized enzyme (E) to the 2-electron reduced form of the enzyme $\left(\mathrm{EH}_{2}\right)$; and in the second, the reoxidation of $\mathrm{EH}_{2}$ to $\mathrm{E}$, electrons pass very rapidly via the FAD to NAD ${ }^{+}$. The distinct roles of the two nascent thiols of $\mathrm{EH}_{2}$ have been demonstrated. ${ }^{10,11}$ The thiol nearer the amino terminus reacts almost exclusively with iodoacetamide, and it is this thiol that interchanges with the dithiol substrate; the sulfur nearer the carboxyl terminus interacts with the FAD. Similar results are seen with glutathione reductase ${ }^{12}$ and mercuric reductase. ${ }^{13}$ The assignment of roles to the two nascent thiols in

\footnotetext{
${ }^{a} \mathrm{~T}$ !his work was supported by the Medical Research Service of the Veterans Administration, by Grant GM21444 from the National Institute of General Medical Sciences (to C. H. W.) and by a Science and Engineering Research Council project grant (to J. R. G.).

${ }^{c}$ Author to whom correspondence should be sent at the V. A. Medical Center (151), 2215 Fuller Road, Ann Arbor, MI 48105.

${ }^{e}$ Current address: Porton Products, Ltd., CAMR, Porton Down, Salisbury SP4 OJG, United Kingdom.

$f$ Current address: Department of Biochemistry, University of Umeå, S-90187 Umeå, Sweden.
} 
thioredoxin reductase has been more difficult because both nascent thiols are reactive with all reagents tried. ${ }^{14}$ This problem is being solved by site-directed mutagenesis. ${ }^{15}$

In addition to the FAD and the redox-active disulfide, a base is essential for catalysis (FIG. 1). Its function is to deprotonate the dihydrolipoamide for nucleophilic attack on the enzyme disulfide. ${ }^{16}$ Glutathione reductase catalysis is in the chemically opposite direction. In this enzyme, the function of the base is to stabilize the nascent interchange thiol as an anion for attack on the glutathione disulfide. ${ }^{12}$ The amino acid sequence ${ }^{17}$ and $\mathrm{X}$-ray crystallographic structure ${ }^{18}$ of human glutathione reductase show that the base is a histidyl residue strongly hydrogen-bonded to a glutamate. ${ }^{19}$ The thiol nearer to the amino terminus is positioned for interchange with glutathione, and the other thiol is nearer to the flavin. Thus, the crystal structure and other types of data agree. The structure of Azotobacter vinelandii lipoamide dehydrogenase, recently derived, appears to be very similar. ${ }^{21}$ It has been suggested that the positive charge of a lysyl residue whose side chain reaches under the flavin ring, from the disulfide compartment to the pyridine nucleotide compartment, modifies the redox potential of the FAD ${ }^{20}$ Three of the mutations described below were used in an attempt to alter slightly the position of this positive charge relative to the flavin ring.

Earlier studies showed that the Escherichia coli enzyme is somewhat more complex than the pig heart enzyme (FIG. 2). Whereas in the latter species $\mathrm{EH}_{2}$ is predominantly the charge transfer complex, in the $E$. coli enzyme at neutral $\mathrm{pH}$, two additional forms are present in significant amounts: in one of these, a proton shift has left the charge transfer thiol protonated and this form is fluorescent; electrons are on the FAD in the other form. ${ }^{22}$

\section{METHODS}

Site-directed mutagenesis of $E$. coli lipoamide dehydrogenase ${ }^{23}$ and thioredoxin reductase ${ }^{15,24,25}$ has been described. The purification and assay of thioredoxin reductase followed established procedures. ${ }^{15}$ An $E$. coli strain, JRG1342, having an Lpd ${ }^{-}$ phenotype $(\triangle a r o P-l p d)^{26}$ and transformed with pJLA504, ${ }^{27}$ expressed the wild-type or mutated lipoamide dehydrogenases from $\lambda$ promoters ${ }^{23}$ and was grown in $6 \times 1$ lof TB broth containing $50 \mu \mathrm{g} / \mathrm{ml}$ ampicillin by shaking in a Lab Line rotary incubator at $30^{\circ} \mathrm{C}$. When the $\mathrm{A}_{600}$ of the cultures reached 0.6 , the temperature was raised to $42^{\circ} \mathrm{C}$ and incubation was continued for $16-17 \mathrm{hr}$. The yield of cells was 5.5,6.0, 7.0, and 5.0

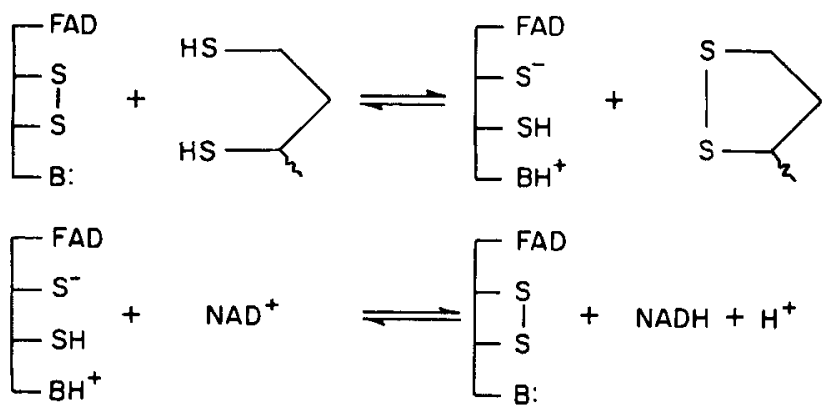

FIGURE 1. Lipoamide dehydrogenase half-reactions: reduction of $\mathrm{E}$ to $\mathrm{EH}_{2}$ by dihydrolipoamide (upper panel) and reoxidation of $\mathrm{EH}_{2}$ to $\mathrm{E}$ by $\mathrm{NAD}^{+}$(lower panel). 


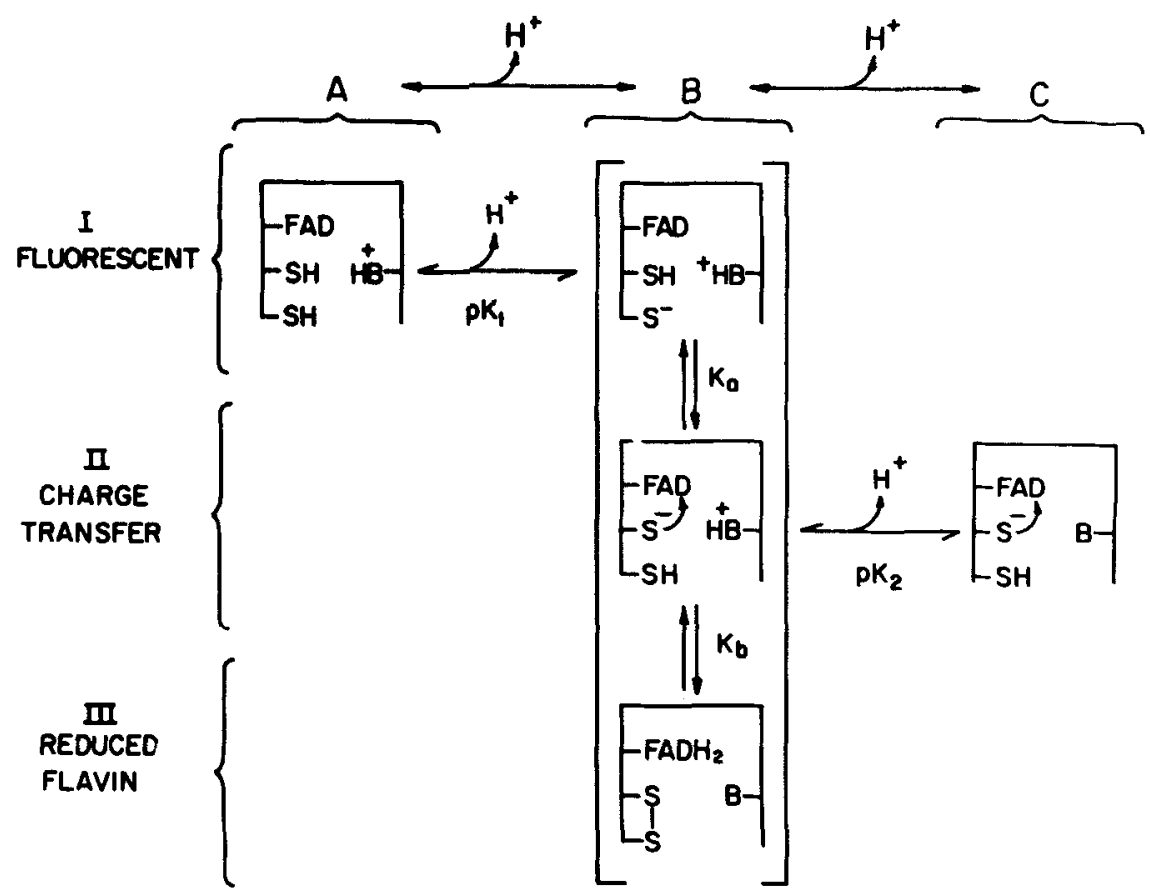

FIGURE 2. Equilibria between species contributing to $\mathrm{EH}_{2}$ in $E$. coli lipoamide dehydrogenase and the effect of $\mathrm{pH}$. A, low $\mathrm{pH} ; \mathbf{B}$, neutral $\mathrm{pH} ; \mathbf{C}$, high $\mathrm{pH}$. (Adapted from Wilkinson \& Williams. ${ }^{22}$ )

g/l for wild type and mutants Glu-188 $\rightarrow$ Asp, ${ }^{g}$ His-444 $\rightarrow$ Gin, and Lys-53 $\rightarrow$ Arg/ Glu-188 $\rightarrow$ Asp, respectively. (The numbering for the $E$. coli lipoamide dehydrogenase amino acid sequence is derived from the nucleotide sequence. ${ }^{28}$ ) Cell were harvested by centrifugation at $6500 \mathrm{rpm}$ for $10 \mathrm{~min}$, homogenized in a minimal volume of $100 \mathrm{mM}$ phosphate buffer, $0.3 \mathrm{mM}$ EDTA, $\mathrm{pH} 7.6$, containing $25 \mu M$ phenylmethylsulfonyl fluoride, and diluted with the same buffer to give $5 \mathrm{ml}$ of suspension $/ \mathrm{g}$ wet cell weight. Cells were broken in a Branson D610 sonifier using a rosette cell immersed in an ice-salt mixture for 5 bursts of 3 min each. Streptomycin sulfate was added to give a final concentration of $2 \%$, and the suspension was spun in a Beckman L8-70M ultracentrifuge, using the VTI-50 rotor, initially at $25,000 \mathrm{rpm}$ for $20 \mathrm{~min}$ and then at $45,000 \mathrm{rpm}$ for an additional hour. The supernatant was fractionated with ammonium sulfate from 35 to $85 \%$ saturation, and the precipitate was dissolved in $100 \mathrm{mM}$ phosphate buffer, $0.3 \mathrm{~m} M$ EDTA, pH 7.6. Following extensive dialysis against $10 \mathrm{~m} M$ phosphate buffer, $0.3 \mathrm{~m} M$ EDTA, $\mathrm{pH} 7.6$ (buffer A), the solution was applied to a DEAE-TRISACRYL (Pharmacia LKB Biotechnology) column, $2.5 \times 11 \mathrm{~cm}$, equilibrated with buffer $\mathrm{A}$. A fraction of protein was eluted by washing with buffer $\mathrm{A}$; elution was continued with a gradient formed from $250 \mathrm{ml}$ each of buffer A, without and with $1 \mathrm{M} \mathrm{NaCl}$. The fraction eluting between 0.16 and $0.2 \mathrm{M} \mathrm{NaCl}$ contained most of the enzyme. After concentration with ammonium sulfate and dialysis against

\footnotetext{
${ }^{8}$ Designation of mutants: Glu-188 $\rightarrow$ Asp, mutation of Glu-188 to Asp.
} 
$50 \mathrm{~m} M$ phosphate buffer, $0.3 \mathrm{~m} M$ EDTA, $\mathrm{pH} 7.6$ (buffer B), it was further purified by adsorption chromatography on a $2.5 \mathrm{~cm} \times 27 \mathrm{~cm}$ calcium phosphate gel column equilibrated with buffer $B$. The column was washed successively with buffer B and buffer $\mathrm{B}$ containing $0.1 \mathrm{M}$ ammonium sulfate, and the enzyme was eluted with buffer B containing $0.3 M$ ammonium sulfate. In the case of the wild-type enzyme, the $\mathrm{A}_{280} / \mathrm{A}_{450}$ ratio was 6.4 and the yield was $85 \mathrm{mg}$.

Since the Glu-188 $\rightarrow$ Asp enzyme did not bind well to calcium phosphate gel, further purification was attempted, following the DEAE step, by apolar chromatography, first on phenyl-Sepharose and then on a hydrophobic interaction column (TSK phenyl-5PW). The yield was poor and the improvement in purity was marginal in both steps; loss of FAD was evident. The $A_{280} / A_{455}$ ratio of the Glu-188 $\rightarrow$ Asp enzyme used in these studies was 11 . The His-444 $\rightarrow$ Gln enzyme was not retained by DEAE. Following chromatography on calcium phosphate gel, it was further purified by apolar chromatography on phenyl-Sepharose. The $A_{280} / A_{455}$ was 7.0 and the yield was 95 mg.

Lipoamide dehydrogenase was assayed by following the reduction of acetylpyridine adenine dinucleotide $\left(\mathrm{APAD}^{+}\right)$by dihydrolipoamide, measured by a change in absorbance at $363 \mathrm{~nm}$, at $25^{\circ} \mathrm{C}$. The assay volume was $2.5 \mathrm{ml}$ of $60 \mathrm{mM}$ phosphate buffer, pH 7.6, containing $0.8 \mathrm{mg} / \mathrm{ml}$ bovine serum albumin, $1.4 \mathrm{~m} M$ EDTA, $400 \mu M$ $\mathrm{APAD}^{+}$, and $80 \mu M$ dihydrolipoamide. The turnover number of the wild type enzyme was approximately $500 \mathrm{~mol} \mathrm{APAD}^{+}$oxidized $/ \mathrm{mol}$ FAD. The turnover number of the Glu-188 $\rightarrow$ Asp mutated enzyme was $1550 \mathrm{~mol} \mathrm{APAD}{ }^{+}$oxidized $/ \mathrm{mol}$ FAD, or approximately 3 times that of wild-type enzyme.

\section{RESULTS AND DISCUSSION}

The nine mutageneses of $E$. coli lipoamide dehydrogenase effected thus far are described in another paper in this volume. ${ }^{29}$ Two of the altered enzymes, the Glu-188 $\rightarrow$ Asp and the His-144 $\rightarrow$ Gln, have been extensively purified. For purified enzyme, it is necessary to use the dihydrolipoamide-acetylpyridine adenine dinucleotide assay. Use of the higher-potential $\mathrm{APAD}^{+}$, rather than of $\mathrm{NAD}^{+}$, overcomes the extreme mixed inhibition of the $E$. coli enzyme by NADH; in addition to product inhibition, $\mathrm{NADH}$ reduces the active intermediate $\mathrm{EH}_{2}$ to the inactive $\mathrm{EH}_{4}$, the 4-electron reduced form of the enzyme. In crude extracts, $\mathrm{NAD}^{+}$can be used as the acceptor, presumably because of a very active NADH oxidase. Recently, we have shown with wild-type enzyme that assays using $\mathrm{NAD}^{+}$as the acceptor are possible in the rapid reaction spectrophotometer, where rates can be established before there is significant buildup of NADH. ${ }^{30}$ Steady-state, stopped-flow traces monitoring NADH production at increasing levels of $\mathrm{NAD}^{+}$showed a pronounced lag at the lowest $\mathrm{NAD}^{+}$ level, while at the highest level, inhibition was apparent within $1.5 \mathrm{~s}$. However, initial rates estimated from the linear phase conformed approximately to a Michaelis-Menten model and quite well to a cooperative binding model. The apparent $V_{\max }$ of $400 \mathrm{~s}^{-1}$ was approximately half that observed with the pig heart enzyme, where the NADH inhibition is much less severe. These studies examining the steady-state kinetics of catalysis in the physiological direction of the reaction, together with earlier investigations of the kinetics in the opposite direction, ${ }^{31}$ as well as the spectral properties of $E$. coli lipoamide dehydrogenase, ${ }^{22}$ will form the basis of our comparisons with the enzyme altered by site-directed mutagenesis.

In three of the mutations, we were seeking to alter the position of the Lys-53 side chain charge relative to the isoalloxazine ring: by shortening the ion-pair side chain, as 
in the Glu-188 $\rightarrow$ Asp mutation, by dispersing the positive charge, as in the Lys$53 \rightarrow$ Arg mutation, or by using a double mutation which should maintain the overall length of the ion pair. This strategy was worked out in a conversation between one of us (C. H. W.) and Professor Georg E. Schulz, University of Freiberg. There are at least three ways the protein might adjust to accommodate such changes: the ion pair might be weakened or broken, the polypeptide chain carrying Glu-188 might move, or the polypeptide chain containing the Lys-53 might move.

The Glu-188 $\rightarrow$ Asp enzyme has been extensively purified. FIGURE 3 shows the absorbance spectrum of this altered enzyme compared with that of the wild-type enzyme. Changes to the absorbance in the visible region are minimal, primarily a lessening of the resolution of the shoulder at $480 \mathrm{~nm}$. Purification of the other two altered enzymes in this group, the Lys-53 $\rightarrow$ Arg and the Lys-53 $\rightarrow$ Arg/Glu-188 $\rightarrow$ Asp, is in progress.

Lipoamide dehydrogenase in which the base, His-444, has been changed to Gin has been purified to virtual homogeneity and has very low activity in the APAD ${ }^{+}$ assay-about 0.3 to $0.4 \%$ that of wild type. Given that the $\mathrm{pH}$ of the assay is 1.7 units below the first $\mathrm{p} K_{\mathrm{a}}$ of dihydrolipoamide, ${ }^{32}$ it would be expected that the activity would be diminished by 50 to 100 times, if the only function of the base is to deprotonate the

FIGURE 3. Absorbance spectra of wild-type and Glu-188 $\rightarrow$ Asp lipoamide dehydrogenases. The proteins were in $10 \mathrm{mM} \mathrm{Na} / \mathrm{K}$ phosphate buffer, pH 7.6, $0.3 \mathrm{~m} M$ EDTA, at $20^{\circ} \mathrm{C}$. Solid line, $39.0 \mu M$ wild-type enzyme; dashed line, $13.6 \mu M$ mutated enzyme.

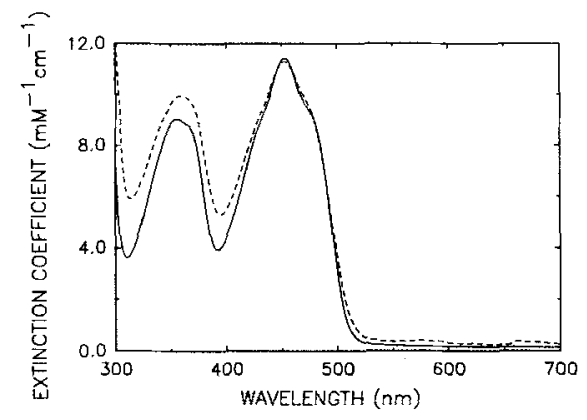

substrate. But, it has been postulated that the base also stabilizes the thiols as thiolates. Absence of this latter function should lead to an additional diminution of activity. Similar levels of activity have been reported for the analogous mutation in glutathione reductase. ${ }^{33}$ FIGURE 4 a shows spectra resulting from titration of this enzyme by dihydrolipoamide. Even in the early phases of the reduction, no detectable charge transfer is seen. Charge transfer is a direct indication of stabilization of the electron transfer thiol as a thiolate. ${ }^{34}$ In a similar equilibrium experiment with the wild-type enzyme (shown in FigURE 4b), ${ }^{35}$ the charge transfer band at $530 \mathrm{~nm}$ is obvious; but, as already discussed, in the $E$. coli enzyme, the charge transfer complex is only one of several species present in $\mathrm{EH}_{2}{ }^{22}$ When the mutated enzyme is reduced in a stopped flow apparatus, (FIG. 5a) sizable charge transfer builds up over the first $30 \mathrm{~s}$. In a similar experiment with the wild-type enzyme, ${ }^{1}$ a high level of charge transfer is almost fully formed in the 3-ms dead time of the rapid-reaction spectrophotometer (FIG. 5b). Thus, in the mutated enzyme, the charge transfer band forms far more slowly and decays more extensively, demonstrating the crucial role of the base in stabilizing the charge transfer complex and, thus, its role in catalysis where the thiolate attacks the FAD.

Conditions for chemical modification of just one of the nascent thiols in $E$. coli 
FIGURE 4. Anaerobic titration of lipoamide dehydrogenase with dihydrolipoamide. Spectra were taken at $20^{\circ} \mathrm{C}$ in conventional spectrophotometers after all changes were complete. (a) Spectra of $18.4 \mu M$ His$444 \rightarrow \mathrm{G} \ln$ enzyme in $0.1 \mathrm{M} \mathrm{Na} / \mathrm{K}$ phosphate buffer, pH 7.6, $0.3 \mathrm{~m} M$ EDTA, titrated with (top to bottom traces, respectively) $0,0.21,0.42,0.63,1.05,1.47$, and $9.87 \mathrm{~mol}$ dihydrolipoamide per mol enzyme FAD. The spectrum of the oxidized enzyme (uppermost curve) overlies that of the enzyme given the first addition of reductant because of incomplete removal of oxygen under these conditions. The small aberration at $550 \mathrm{~nm}$ is due to imperfect baseline correction. (b) Spectra of 23.5 $\mu M$ wild-type enzyme in $0.1 M \mathrm{Na} / \mathrm{K}$ phosphate buffer, pH 7.6, 1.0 m $M$ EDTA, $30 \mathrm{mM}$ ammonium sulfate, titrated with the indicated amounts (mol) of dihydrolipoamide per mol enzyme FAD or, finally, with dithionite.
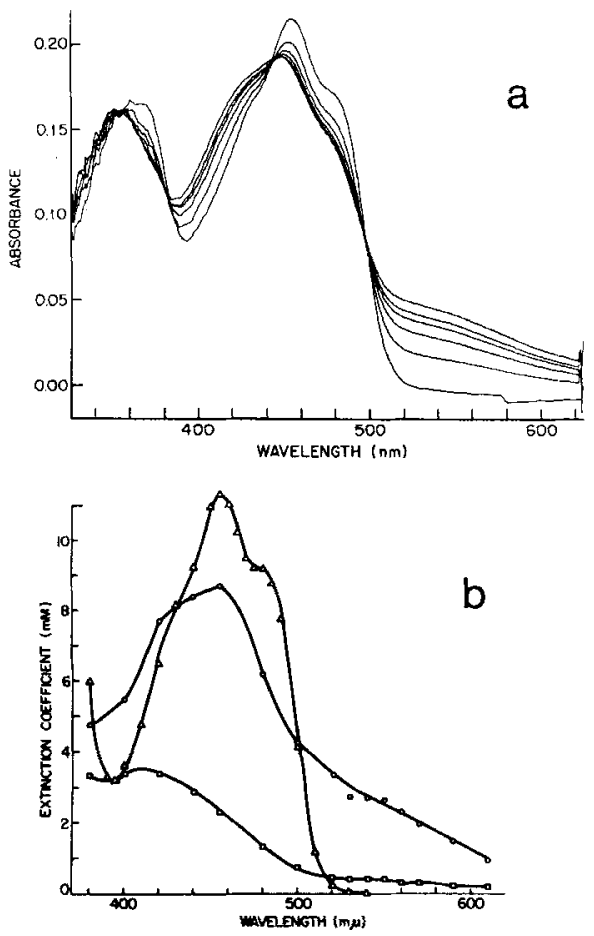
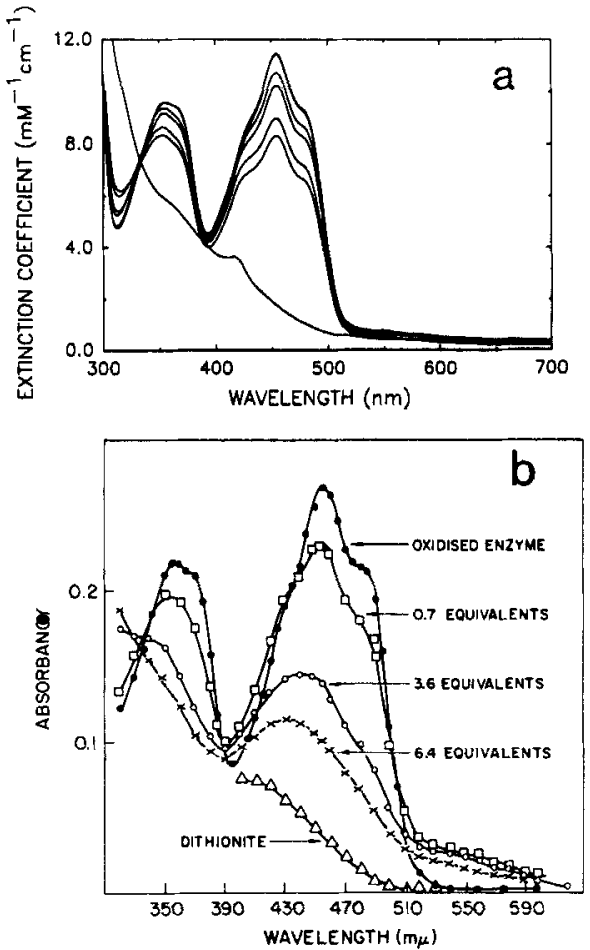

FIGURE 5. Anaerobic reduction of lipoamide dehydrogenase with dihydrolipoamide. (a) Spectra of His-444 $\rightarrow$ Gln enzyme were taken, after rapid mixing (ca. $5 \mathrm{~ms}$ ), using a Tracor Northern diode array spectrometer as the detector. Buildup of charge transfer absorbance $\left(\mathrm{EH}_{2}\right)$ at 550 $\mathrm{nm}$ at (bottom to top traces, respectively) $0,3,6,9,12$, and $30 \mathrm{~s}$ upon reduction with $5.6 \mathrm{~mol}$ of dihydrolipoamide per mol enzyme FAD; enzyme was $9.5 \mu M$ in 0.12 $M \mathrm{Na} / \mathrm{K}$ phosphate buffer, $\mathrm{pH} 7.6,0.3$ $\mathrm{m} M$ EDTA, at $20^{\circ} \mathrm{C}$ after mixing $(2-\mathrm{cm}$ light path). (b) Spectra of wild-type enzyme: $(\Delta)$ oxidized enzyme, $(\mathrm{O}) \mathrm{EH}_{2}$, ( $\square$ ) $\mathrm{EH}_{4}$. Spectra of the oxidized and $\mathrm{EH}_{4}$ forms were taken in a conventional spectrophotometer. The composite spectrum of the $\mathrm{EH}_{2}$ form was generated in a series of identical mixings of enzyme with $11 \mathrm{~mol}$ dihydrolipoamide per mol enzyme FAD in a rapid reaction spectrophotometer with the detector set at the indicated wavelengths. The enzyme was $18 \mu M$ in $0.1 M$ $\mathrm{Na} / \mathrm{K}$ phosphate buffer, $\mathrm{pH} 7.6,0.3 \mathrm{mM}$ EDTA, at $1^{\circ} \mathrm{C}$ after mixing (2-cm light path). 
thioredoxin reductase (TRR) were not found, ${ }^{14}$ and it was therefore not possible to assign distinct functions to these thiols as had been done with lipoamide dehydrogenase and glutathione reductase. ${ }^{10,12}$ Therefore, site-directed mutagenesis has been used to singly modify each thiol to a serine. The properties of the mutated enzymes have allowed us to assign distinct functions to each of the thiols, at least tentatively. ${ }^{15}$ FIGURE 6 shows the spectra of the two mutants compared with that of the wild-type enzyme. The differences between the traces may appear unimpressive, but they suggest which cysteine is nearer the FAD. The resolved character of the spectrum of the wild-type enzyme is due to the apolar milieu of the FAD.$^{36}$ For the mutated enzyme in which Cys-136 has been changed to serine [TRR(Ser-136,Cys-139)], the spectrum still shows the resolution characteristic of the wild-type enzyme. But in the enzyme

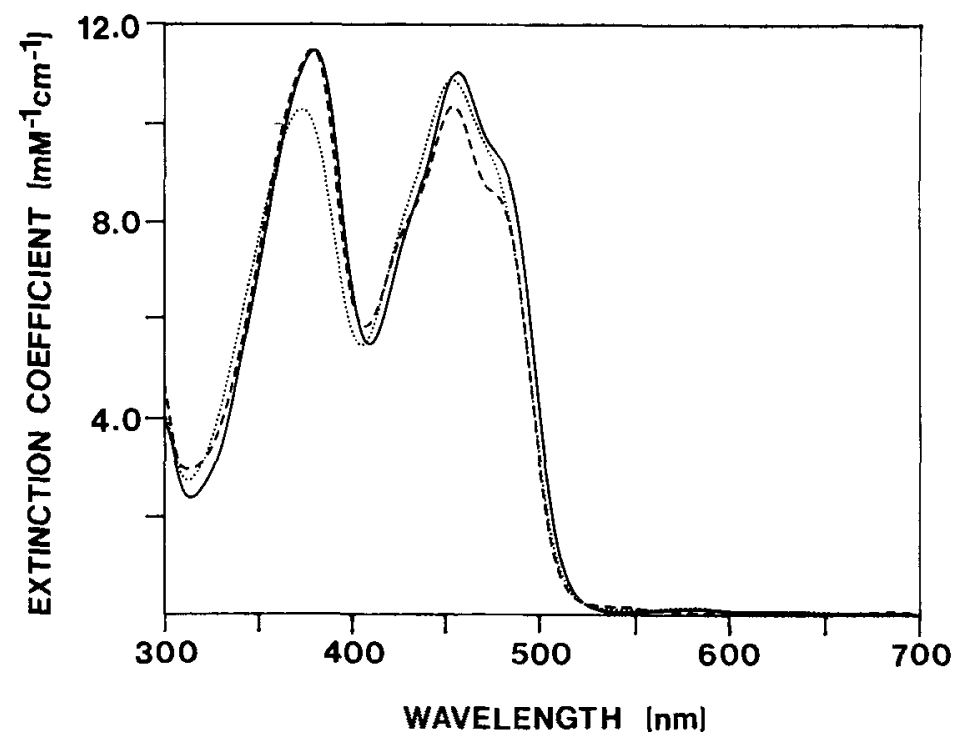

FIGURE 6. Absorbance spectra of wild-type thioredoxin reductase (TRR) and of proteins singly mutated at each thiol group. The proteins were in $0.1 \mathrm{MNa} / \mathrm{K}$ phosphate buffer, $\mathrm{pH} 7.6,0.3 \mathrm{mM}$ EDTA, at $12^{\circ} \mathrm{C}$. Solid line, $18.0 \mu M$ (wild type) TRR(Cys-136,Cys-139); dashed line, $18.8 \mu M$ TRR(Ser-136,Cys-139); dotted line, 18.5 $\mu M$ TRR(Cys-136,Ser-139).

which contains Cys-139 substituted with serine [TRR(Cys-136,Ser-139)], the resolved character is lost. This suggests that Cys-139 is closer to the FAD, since the change of this residue to the more polar serine is reflected in an alteration of the flavin spectrum to one characteristic of a more polar milieu.

While purifying the TRR(Ser-136,Cys-139) enzyme, we observed that it turned red upon the addition of ammonium sulfate. This was unexpected, since $E$. coli thioredoxin reductase has not previously been observed to stabilize the charge transfer complex. ${ }^{37}$ As shown in Figure 7 , ammonium ion causes the appearance at long wavelengths of a band very similar in shape to that of the lipoamide dehydrogenase and glutathione reductase charge transfer complexes.' An apparent $K_{d}$ of $54 \mu M$ can be calculated after correction for non-specific binding (FIG. 7, inset). Only a limited 


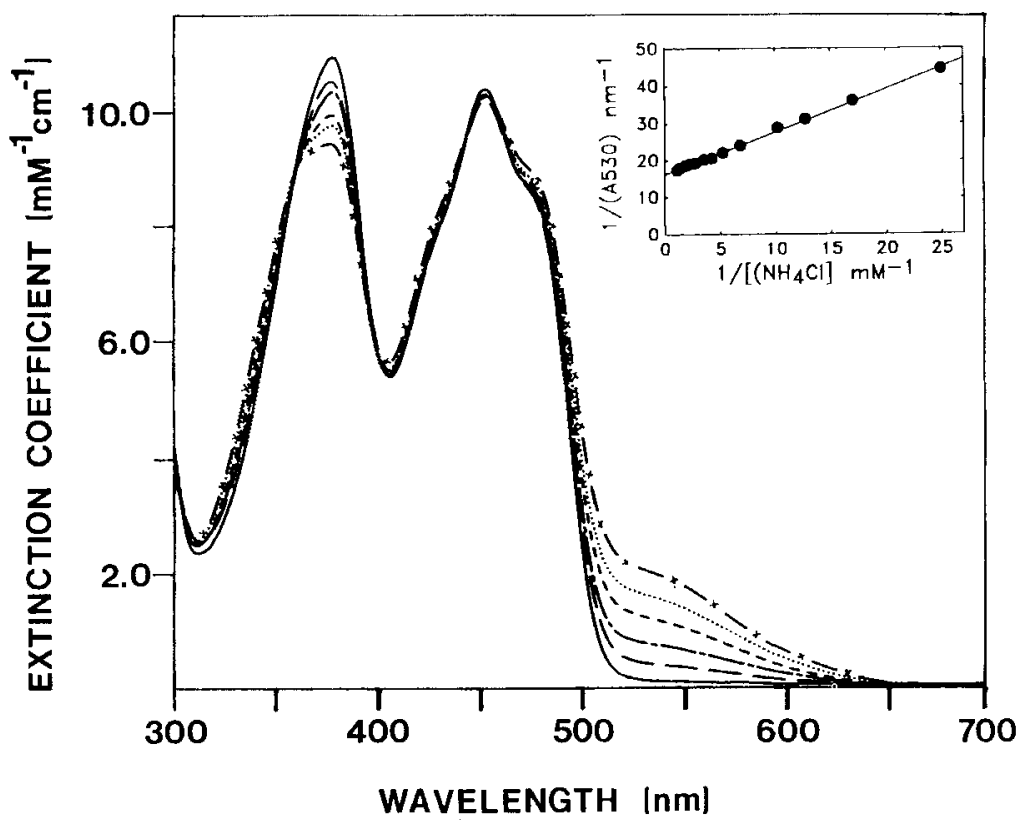

FIGURE 7. Titration of TRR(Ser-136,Cys-139) with $5 M \mathrm{NH}_{4} \mathrm{Cl} .42 .4 \mu M$ TRR(Ser-136,Cys139 ) in $0.1 \mathrm{M} \mathrm{Na} / \mathrm{K}$ phosphate buffer, $\mathrm{pH} 7.6,0.3 \mathrm{mM}$ EDTA, was titrated at $12^{\circ} \mathrm{C}$ with a $5 \mathrm{M}$ $\mathrm{NH}_{4} \mathrm{Cl}$ solution in $0.1 \mathrm{M} \mathrm{Na} / \mathrm{K}$ phosphate buffer, $0.3 \mathrm{mM}$ EDTA, $\mathrm{pH}$ adjusted to maintain the $\mathrm{pH}$ of the enzyme solution at 7.6 throughout the titration. (-) no $\mathrm{NH}_{4} \mathrm{Cl},(--) 79 \mathrm{mM} \mathrm{NH} \mathrm{N}_{4} \mathrm{Cl}$, $\left(--\right.$ - $\left.^{-}\right) 98 \mathrm{mM} \mathrm{NH} \mathrm{m}_{4} \mathrm{Cl},(--) 192 \mathrm{mM} \mathrm{NH}_{4} \mathrm{Cl} ;(\ldots) 455 \mathrm{mM} \mathrm{NH}_{4} \mathrm{Cl}$, and $(-\mathrm{x}-\mathrm{x}-) 833 \mathrm{mM}$ $\mathrm{NH}_{4} \mathrm{Cl}$. Inset: Benesi-Hildebrand plot of the titration; $K_{\mathrm{d}}, 54 \mu M ; \mathrm{E}_{530}, 1300 M^{-1} \mathrm{~cm}^{-1}$.

number of ions have been tried, but ammonium ion is thus far unique in causing the effect. This result reinforces the suggestion that it is Cys-139 that is interacting with the FAD. If, as with other members of this enzyme family, the two distinct catalytic functions are each carried out by a different nascent thiol, then Cys-136 would perform the initial thiol-disulfide interchange with thioredoxin.

The finding that both thiol-altered enzymes were partially active was totally unexpected. ${ }^{15}$ The analogous mutated enzymes in mercuric reductase ${ }^{38}$ and lipoamide dehydrogenase ${ }^{29}$ were totally without activity in their physiological reactions. The steady-state kinetics of the mutated enzymes have been compared with those of the wild-type enzyme in assays of NADPH-thioredoxin activity linked to 5,5'-dithiobis(2nitrobenzoic acid) reduction, in which the NADPH concentration was kept constant by glucose-6-phosphate and glucose-6-phosphate dehydrogenase. The $K_{\mathrm{m}}$ values were little changed. The TRR(Ser-136,Cys-139) enzyme had just over $10 \%$ activity while the TRR(Cys-136,Ser-139) enzyme appeared to have a $V_{\max }$ of about $50 \%$ of the wild type. However, with the latter mutant enzyme, the intercept replots of the parallel Lineweaver-Burk plots were not linear, and the $V_{\max }$ was extrapolated from the data points for the two highest concentrations. It was therefore an upper limit. It has been suggested, based on the chemical modification studies and from the fact that the substrate for thioredoxin reductase is itself a protein, that the site of thiol-disulfide interchange must be more open in this enzyme than in other members of this enzyme 
family. ${ }^{14}$ It would appear, then, that in this more open active site, the remaining thiol in either mutation of thioredoxin reductase can fairly readily form a mixed disulfide with thioredoxin and that either of these can be reduced by $\mathrm{FADH}_{2}$. This is in contrast to lipoamide dehydrogenase, where only one of the sulfurs can be attacked by the dithiol substrate, or to glutathione reductase, where only one of the nascent thiols can interchange with glutathione. Furthermore, in both these enzymes, interaction with FAD is the unique function of only one of the sulfurs. However, in the mutated thioredoxin reductase enzymes, no new chemistry is required.

FIGURE 8 shows mechanisms for the reoxidation by thioredoxin of each of the two mutated enzymes and indicates the step thought to be partially blocked and thus responsible for their reduced catalytic activities. This picture attempts to suggest that whereas in glutathione reductase the electron transfer thiol and the interchange thiol lie on a line perpendicular to the flavin ring-so that only the electron transfer thiol can interact with the $\mathrm{FAD}^{19}$ - in thioredoxin reductase the thiols may lie on a less perpendicular line. If the proposal that Cys-139 normally interacts with the FAD is correct, the activity of TRR(Cys-136,Ser-139) (lower line in FIG. 8) would be limited by inefficient electron transfer directly from $\mathrm{FADH}_{2}$ to the mixed disulfide, since this step would have to replace the thiol-disulfide interchange normally initiated by Cys-139. The fact that mutation of Cys-136 to serine results in substantial loss of activity suggests that both thiols have distinct functions, leading to a working hypothesis that Cys-136 is the interchange thiol. Then the activity of TRR(Ser136,Cys-139) (upper line in FIG. 8) would be limited by inefficient thiol-disulfide interchange with oxidized thioredoxin initiated by Cys-139. The suggested mechanisms for activity in each mutated enzyme re-emphasize the more open active site required by thioredoxin reductase compared to related enzymes in order to accommo-

TRR (Ser 136 Cys 139)

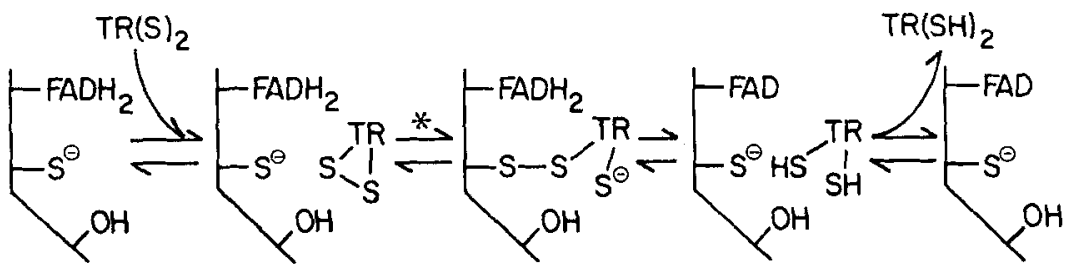

$\operatorname{TRR}$ (Cys 136 Ser 139)

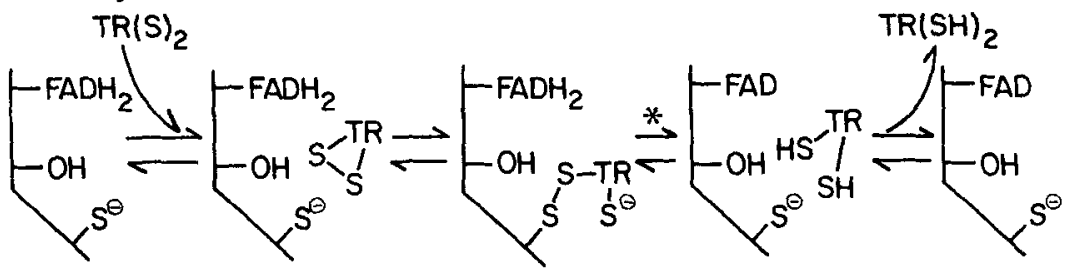

FIGURE 8. Reduction of thioredoxin by reduced forms of (upper panel) TRR(Ser-136,Cys-139) and (lower panel) TRR(Cys-136,Ser-139). The position of steps possibly responsible for catalytic inefficiencies are indicated by asterisks. $\mathrm{TR}(\mathrm{S})_{2}$ and $\mathrm{TR}(\mathrm{SH})_{2}$ are the oxidized and reduced forms of thioredoxin, respectively. 
date its protein substrate. However, we are not suggesting that wild-type enzyme is any less specific in dithiol-disulfide interchange than are the other members of this enzyme family.

\section{ACKNOWLEDGMENTS}

The authors wish to thank Daniel Domain and David Gamm for help in purifying the enzymes and Eric Baude for assistance in the dihydrolipoamide reductions of the His- $444 \longrightarrow$ Gln mutated enzyme.

\section{REFERENCES}

1. Williams, C. H. JR. 1976. Flavin-containing dehydrogenases. In The Enzymes, 3rd ed. P. D. Boyer, Ed. Vol. XIII: 89-173. Academic Press. New York.

2. Williams, C. H. JR., L. D. ArScotT \& G. E. Schulz. 1982. Amino acid sequence homology between pig heart lipoamide dehydrogenase and human erythrocyte glutathione reductase. Proc. Natl. Acad. Sci. USA 79: 2199-2201.

3. Rice, D. W., G. E. Schultz \& J. R. Guest. 1984. Structural relationship between glutathione reductase and lipoamide dehydrogenase. J. Mol. Biol. 174: 483-496.

4. Brown, N. L., S. J. Ford, R. D. Pridmore \& D. C. Fritzinger. 1983. DNA sequence of a gene from the Pseudomonas transposon TN501 encoding mercuric reductase. Biochemistry 22: 4089-4095.

5. Greer, S. \& R. N. Perham. 1986. Glutathione reductase from Escherichia coli: Cloning and sequence analysis of the gene and relationship to other flavoprotein disulfide oxidoreductases. Biochemistry 25: 2736-2742.

6. RuSSEL, M. \& P. MODEL. 1988. Sequence of thioredoxin reductase from Escherichia coli: Relationship to other flavoprotein disulfide oxidoreductases. J. Biol. Chem. 263: 90159019.

7. Massey, V., Q. H. GibSON \& C. Veeger. 1960. Intermediates in the catalytic action of lipoyl dehydrogenase. Biochem. J. 77: 341-351.

8. MASSEY, V. \& C. VEEGER. 1961. Studies on the reaction mechanism of lipoyl dehydrogenase. Biochim. Biophys. Acta 48: 33-47.

9. Searls, R. L., J. M. Peters \& D. R. Sanadi. 1961. $\alpha$-Ketoglutaric dehydrogenase: On the mechanism of dihydrolipoly dehydrogenase reaction. J. Biol. Chem. 236: 2317-2322.

10. ThORPE, C. \& C. H. Williams, JR. 1976. Differential reactivity of the two active site cysteine residues generated on reduction of pig heart lipoamide dehydrogenase. J. Biol. Chem. 251: 3553-3557.

11. ThORPE, C. \& C. H. Williams, JR. 1976. Spectral evidence for a flavin adduct in a monoalkylated derivative of pig heart lipoamide dehydrogenase. J. Biol. Chem. 251: 7726-7728.

12. ARSCOTT, L. D., C. Thorpe \& C. H. Williams, JR. 1981. Glutathione reductase from yeast-Differential reactivity of the nascent thiols in two-electron reduced enzyme and properties of a monoalkylated derivative. Biochemistry 20: 1513-1520.

13. Fox, B. S. \& C. T. WALSH. 1983. Active site peptide of mercuric reductase: Homology to glutathione reductase and lipoamide dehydrogenase. Biochemistry 22: 4082-4088.

14. O'DonNell, M. E. \& C. H. Williams, JR. 1985. Reaction of both thiols of reduced thioredoxin reductase with $N$-ethyl maleimide. Biochemistry 24: 7617-7621.

15. Prongay, A. J., D. R. Engelke \& C. H. Williams, JR. 1989. Characterization of two active site mutants of thioredoxin reductase from Escherichia coli. J. Biol. Chem. 264: 2656-2664.

16. MatThews, R. G. \& C. H. Williams, JR. 1976. Measurement of the oxidation-reduction potentials for two electron and four electron reduction of lipoamide dehydrogenase from pig heart. J. Biol. Chem. 251: 3956-3964.

17. Untucht-Grau, R., G. E. Schulz \& R. H. Schirmer. 1979. The C-terminal fragment of 
human giutathione reductase contains the postulated catalytic histidine. FEBS Lett. 105: $244-248$.

18. SChUlz, G. E., R. H. Schirmer, W. SaChSenheimer \& E. F. Pai. 1978. The structure of the flavoenzyme glutathione reductase. Nature 273: 120-124.

19. KARPLUS, P. A. \& G. E. SchulZ. 1987. Refined structure of glutathione reductase at 1.54 Å resolution. J. Mol. Biol. 195: 701-729.

20. PAI, E. F. \& G. E. Schulz. 1983. The catalytic mechanism of glutathione reductase as derived from X-ray diffraction analyses of reaction intermediates. J. Biol. Chem. 258: $1752-1757$.

21. SCHIERBECK, B. 1988. The three-dimensional structure of lipoamide dehydrogenase from Azotobacter vinlandii. Thesis. Groningen University. pp. 74-76.

22. Wilkinson, K. D. \& C. H. Williams, JR. 1979. Evidence for multiple electronic forms of two electron reduced lipoamide dehydrogenase from Escherichia coli. J. Biol. Chem. 254: 852-862.

23. Allison, N., C. H. Williams, JR. \& J. R. Guest. 1988. Overexpression and mutagenesis of the lipoamide dehydrogenase of Escherichia coli. Biochem. J. 256: 741-749.

24. RuSSEL, M. \& P. Model. 1985. Direct cloning of the $\operatorname{tr} x \mathrm{~B}$ gene that encodes thioredoxin reductase. J. Bacteriol. 163: 238-242.

25. RUSSEL, M. \& P. MODEL. 1986. The role of thioredoxin in filamentous phage assemblyConstruction, isolation and characterization of mutant thioredoxins. J. Biol. Chem. 261: $14997-15005$.

26. Guest, J. R., H. M. Lewis, L. D. Graham, L. C. Packman \& R. N. Perham. 1985. Genetic reconstruction and functional analysis of the repeating lipoyl domains in the pyruvate dehydrogenase multienzyme complex of Escherichia coli. J. Mol. Biol. 185: 743-754.

27. Schauder, B., R. Frank, H. Blocker \& J. E. G. MCCarthy, 1987. Inducible expression vectors incorporating the Escherichia coli atpE translational initiation region. Gene 52: $297-283$.

28. Stephens, P. E., H. M. Lewis, M. G. DARLison \& J. R. Guest. 1983. Nucleotide sequence of the lipoamide dehydrogenase gene of Escherichia coli K12. Eur. J. Biochem. 135: 519-527.

29. Russell, G. C., N. J. Allison, C. H. Williams, JR. \& J. R. Guest. 1989. Oligonucleotide-directed mutagenesis of the lpd gene of Escherichia coli. Ann. N. Y. Acad. Sci. This volume.

30. Sahlman, L. \& C. H. Williams, JR. 1989. Lipoamide dehydrogenase from Escherichia coli-Steady-state kinetics of the physiological reaction. J. Biol. Chem. 264: 80398045 .

31. Wilkinson, K. D. \& C. H. WILlIAMS, JR. 1981. NADH inhibition and NAD activation of Escherichia coli lipoamide dehydrogenase catalyzing the NADH-lipoamide reaction. J. Biol. Chem. 256: 2307-2314.

32. Matthews, R. G., D. P. Ballou, C. Thorpe \& C. H. Williams, JR. 1977. Ion pair formation in pig heart lipoamide dehydrogenase-Rationalization of $\mathrm{pH}$ profiles for reactivity of oxidized enzyme with dihydrolipoamide and 2-electron-reduced enzyme with lipoamide and iodoacteamide. J. Biol. Chem. 252: 3199-3207.

33. Berry, A., N. S. Scrutton \& R. N. Perham. 1989. Switching kinetic mechanism and putative proton donor by directed mutagenesis of glutathione reductase. Biochemistry 28: $1264-1269$.

34. MASSEY, V. \& S. GhiSLA. 1974. Role of charge transfer interactions in flavoprotein catalysis. Ann. N. Y. Acad. Sci. 227: 446-465.

35. Williams, C. H., JR. 1965. Studies on lipoyl dehydrogenase from Escherichia coli. J. Biol. Chem. 240: 4793-4800.

36. Palmer, G. \& V. MASSEY. 1968. Mechanisms of flavoprotein catalysis. In Biological Oxidations. T. P. Singer, Ed.: 263-300. Interscience. New York.

37. O'Donnell, M. E. \& C. H. Williams, JR. 1983. Proton stoichiometry in the reduction of the FAD and disulfide of Escherichia coli thioredoxin reductase-Evidence for a base at the active site. J. Biol. Chem. 258: 13795-13805.

38. Schultz, P. G., K. G. AU \& C. T. WALSh. 1985. Directed mutagenesis of the redox-active disulfide in the flavoenzyme mercuric ion reductase. Biochemistry 24: 6840-6848. 